\title{
Experimental Study on Soil Electrical Conductivity Inversion by Ground Spectral Measurement and SAR Data
}

\author{
Yin Chengshen, Liu Quanming*, Wang Chunjuan, Wang Fuqiang \\ College of Water Conservancy and Civil Engineering, Inner Mongolia Agricultural University, Hohhot, China \\ Email address: \\ 1572266410@qq.com (Yin Chengshen),nndlqm@sina.com (Liu Quanming),w15938965005@163.com (Wang Chunjuan), \\ 1692514273@qq.com (Wang Fuqiang) \\ ${ }^{*}$ Corresponding author
}

\section{To cite this article:}

Yin Chengshen, Liu Quanming, Wang Chunjuan, Wang Fuqiang. Experimental Study on Soil Electrical Conductivity Inversion by Ground Spectral Measurement and SAR Data. Science Discovery. Vol. 9, No. 4, 2021, pp. 200-205. doi: 10.11648/j.sd.20210904.22

Received: July 16, 2021; Accepted: August 13, 2021; Published: August 23, 2021

\begin{abstract}
In this paper, the ground-measured spectral reflectance was combined with C-band microwave radar quadrupolarized backscattering data, and the characteristic bands were selected using partial least squares and correlation coefficient methods, and a model was developed to evaluate the degree of soil salinization. Using the spectral reflectance and its logarithmic, first-order and second-order derivatives of the four spectral data, correlation analysis was performed and found that the first and second order derivatives of the spectra were better correlated compared to the first two. The correlations of soil EC values in the four bands of 1584-1588 nm, 1802-1806 nm, 2201-2205 nm, and 2344-2348 nm transformed by second-order derivatives were $0.27,0.34,0.33$, and 0.35 , respectively, and there existed two bands of $1802-1806 \mathrm{~nm}$ and $2344-2348 \mathrm{~nm}$ that both had better soil EC correlation. The bands selected by the partial least squares method are more backward than those selected by the correlation coefficient method, and there are extremely sensitive bands, and the fit of the second-order derivative transformation model is better compared with that of the correlation coefficient method. By combining the second-order derivatives of reflectance, surface roughness and radar backscatter coefficients, the neural network model with the second-order derivatives of reflectance and radar backscatter characteristics was the best prediction model, and its $\mathrm{R}^{2}$ for soil EC was 0.8666 .
\end{abstract}

Keywords: Soil Conductivity, Multi-source Remote Sensing, Collaborative Inversion, Partial Least Squares Method, The Neural Network

\section{地面光谱测量协同SAR数据联合反演土壤电导率实验研究}

尹承深, 刘全明“, 王春娟, 王福强

内蒙古农业大学水利与土木建筑工程学院, 呼和浩特, 中国

邮箱

1572266410@qq.com（尹承深）, nndlqm@sina.com（刘全明）, w15938965005@163.com（王春娟）, 1692514273@qq.com（王福强）

摘要: 本文利用地面实测光谱反射率, 结合 $\mathrm{C}$ 波段微波雷达四极化后向散射数据, 利用偏最小二乘法和相关系数法选 取特征波段, 并且建立模型用于评价土壤的盐渍化程度。利用光谱反射率及其对数、一阶与二阶导数四种光谱数据, 进行相关性分析发现相较于前两者，光谱的一、二阶导数的相关性更好。土壤EC值在二阶导数变换的 $1584-1588 \mathrm{~nm}$ 、 $1802-1806 \mathrm{~nm} 、 2201-2205 \mathrm{~nm} 、 2344-2348 \mathrm{~nm}$ 四个波段相关性分别为 $0.27 、 0.34 、 0.33 、 0.35$, 存在 $1802-1806 \mathrm{~nm}$ 和 2344-2348nm两个波段对土壤EC都具有较好的相关性。偏最小二乘法篮选的波段相较相关系数法选取的波段较偏后， 且存在极为敏感的波段，其二阶导数变换模型的拟合度与相关系数法相比更优。通过协同光谱特征波段反射率二阶导 数、地表粗粘度和雷达后向散射系数等诸多影响因子，对比土壤EC的多元回归模型，协同雷达后向散射特性与反射率 
二阶导数的神经网络模型是最优预测模型, 其对土壤 $E C$ 的预测 $\mathrm{R}^{2}$ 为 0.8666 , 其模型的预测精度和稳定性均优于多元线 性回归模型。

关键词：土壤电导率，多源遥感，协同反演，偏最小二乘法，神经网络

\section{1. 引言}

土地盐渍化已经成为土地荒漠化和土地退化的主要 原因之一[1], 河套灌区的耕地由于综合因素部分土地出现 了积盐、积碱等土壤盐渍化现象, 土地退化和废弃状况严 重[2]。因此，高效监测和准确定量预测大区域尺度的土壤 盐碱度, 对灌区农业可持续发展具有重大的意义。野外土 壤定点取样方法动态性差, 不能满足农业研究要求, 无法 代表区域的盐渍程度, 然而遥感技术为河套灌区实时动态 监测盐渍土状况提供了可能 [3]。

国外利用遥感监测土壤盐碱性始于上个世纪70年代 [4][7]，80年代国内已经开始将遥感可见光波段来反演土 壤盐分, 由于盐渍化土壤参数与光谱反射率之间的转换是 非线性的复杂联系 [8], 因此人工神经网络逐渐用来获取盐 渍化参数 [9-13]。刘全明等[14]基于盐分值与雷达后向散射 系数, 构建了解放闸灌域BP ANN土壤含盐量的定量反演 模型, 且与地面验证结果基本一致。孙艺珊 [15]以吉林省 西部松嫩平原为研究区, 基于机器学习算法建立了盐渍土 电导率遥感反演模型, 高斯过程回归模型表现最优。尼格 拉. 塔什甫拉提 [16]以植被和土壤的综合光谱特征为重要 参数, 利用实测数据与多源遥感数据反演新疆绿洲土壤电 导率, 其结论是土壤电导率实测值与反演值相关性为 0.873 。牛涛[17]采用遥感与电导率仪技术相结合对新疆渭 干河一库车河三角洲绿洲半干旱地区土壤电导率的时空 变化进行调查, 建立了基于实测数据和遥感数据相结合的 克里格插值法的电导率反演模型。郭姝姝 [18]结合遥感数 据及实测土壤电导率值, 建立耕地表层土壤含盐量反演模 型, 获得了修改型土壤调整植被指数MSAVI和土壤盐分指 数SI3构建的耕地表土盐分反演模型精度最高。彭杰等[19] 分析高光谱数据和实测盐分与电导率数据, 研究了南疆水 稻耕作土壤含盐量与电导率的关系, 比较了含盐量和电导 率与不同光谱指标的相关性以及二者高光谱反演的精度。

利用测得的电导率, 能够较精确地计算土壤含盐量 [20]。文章选择高光谱土壤电导率特征波段, 融合后向散 射系数, 构建了基于多源遥感数据的农业土壤电导率预测 模型, 为利用多源遥感数据协同反演盐渍土时空分布提供 科学基础[21]。

\section{2. 研究区概况}

河套灌区北纬 $40^{\circ} 12^{\prime}-41^{\circ} 20^{\prime}$, 东经 $106^{\circ} 10^{\prime}-109^{\circ} 30^{\prime}$ 。该 区地形较为平坦, 海拔约 $1007-1050 \mathrm{~m}$ 。年降水量为 100- $250 \mathrm{~mm}$, 蒸发量高达 $2400 \mathrm{~mm}$, 典型的温带大陆性气 候。灌区灌溉面积 $5583 \mathrm{~km}^{2}$, 不仅降水少而且蒸发量大、 土壤次生盐渍化现象严重, 那么及时准确地掌握该区域夏
灌（4-6月）前土壤盐分分布情况对灌溉等具有重要意义 [22]。

\section{3. 材料与方法}

\section{1. 数据获取与处理}

研究区为巴彦淖尔市的解放闸灌域。遥感数据为 2016 年4月6日RADARSAT-2精细四极化SLC格式雷达影像, $8 \mathrm{~m}$ 的分辨率 [23]。结合土壤盐分统计资料选取 89 个采样 点, 制定采样的路线, 采样点分布见图1。实验过程中通 过手持GPS仪测量各采样点经纬度坐标, 利用剖面板上有 厘米网格的方法对地表粗糙度测量[24], 各个取样点土壤 表土3份装袋，在实验室测量电导率。

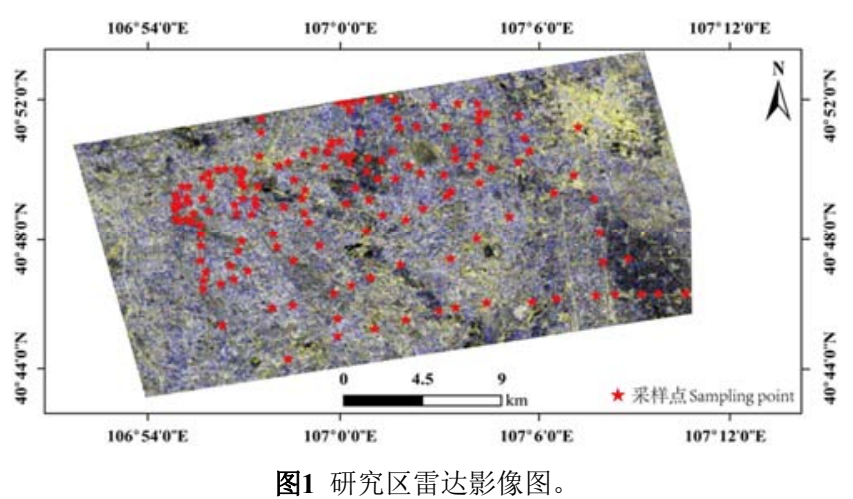

本文在SAR Scape模块对雷达数据如下操作: 多视、 滤波、地理编码和辐射定标[25], 在相关影像对雷达数据 几何配准, 获得四极化后向散射系数 [26], 研究区部分取 样点后向散射系数与地表粗糙度、EC值见表1。

Field Spec4便携式光谱仪用于取样点土壤反射率光 谱数据的采集, 仪器详细介绍见文献[27]。在光谱仪本身 自带软件中将光谱反射率 $\mathrm{R}$ 变换三种不同形式: 一阶导数、 二阶导数和以 10 为底的对数形式, 输入数据是 3 种变换光 谱及地面反射率 [21], 后期将 4 种输入值与对应点位盐分值 进行相关性分析等。

\section{2. 相关系数与逐步回归分析法MSR (Multiple Stepwise Regress, MSR）简介}

相关分析实测土壤 $\mathrm{EC}$ 值与反射率及变换形式各波 段, 得到每一光谱波段与土壤 $\mathrm{EC}$ 的相关性系数, 选择相 关系数较大波段用于多元逐步线性回归分析, 从而建立光 谱反射率二阶微分、后向散射系数及组合粗糙度与土壤全 盐量之间的回归方程[28]。

MSR 是将每个变量依次引进到模型, 当引入解释变 量时需要 $\mathrm{F}$ 检验, 对所选入的解释变量逐次 $\mathrm{t}$ 检验。如果 引进的解释变量因为后续解释变量的引进导致不再显 
著, 删除回归方程中不显著解释变量, 确保加入新变量 前仅有显著变量[29]。此剔除过程通常是反复地多次进 行, 一直到回归方程没有显著解释变量再次选入, 也不 再剔除任何不显著的解释变量为止, 得到最终解释变量 为最佳[30]。

\subsection{PLSR简介}

PLSR是一种多因素变量对多自变量的回归建模[31], 能够解决以往用普通多元回归无法解决的难题, 通过使用 波段权重值显示波段于土壤 $\mathrm{EC}$ 值的灵敏度，从而选择对 $\mathrm{EC}$ 值敏感的显著波段来对土壤EC回归模型拟合[21]。

表1 遥感影像后向散射系数与土壤原始数据表。

\begin{tabular}{|c|c|c|c|c|c|c|}
\hline 采样点号 & $\mathbf{S}_{\mathrm{HH}} / \mathbf{d B}$ & $\mathrm{S}_{\mathrm{HV}} / \mathrm{dB}$ & $\mathrm{S}_{\mathrm{VH}} / \mathrm{dB}$ & $\mathrm{S}_{\mathrm{Vv}} / \mathrm{dB}$ & 组合粗糙度 $\mathbf{z}_{\mathrm{s}} / \mathbf{c m}$ & $\mathrm{EC} \mathrm{mS} / \mathrm{cm}$ \\
\hline 1 & -13.3934 & -18.501 & -17.8987 & -13.5632 & 0.02 & 0.69 \\
\hline 2 & -7.1398 & -17.676 & -17.2772 & -6.077 & 0.03 & 1.92 \\
\hline 3 & -12.5476 & -26.9471 & -26.8925 & -12.7962 & 0.07 & 0.85 \\
\hline 4 & -7.4233 & -19.0669 & -18.8235 & -7.4401 & 0.01 & 0.22 \\
\hline 5 & -12.2658 & -20.0181 & -19.4655 & -13.3368 & 0.01 & 0.35 \\
\hline 6 & -11.7375 & -23.846 & -24.7555 & -11.7683 & 0.03 & 0.75 \\
\hline 7 & -7.7485 & -20.793 & -20.5346 & -8.0668 & 0.02 & 1.21 \\
\hline 8 & -10.575 & -21.9309 & -22.1844 & -10.2971 & 0.01 & 0.26 \\
\hline 9 & -10.3825 & -19.4305 & -18.4422 & -10.6687 & 0.15 & 0.48 \\
\hline 10 & -3.5261 & -17.5361 & -16.6864 & -9.8457 & 0.02 & 0.55 \\
\hline 11 & -10.093 & -19.9892 & -19.5134 & -12.3084 & 0.02 & 0.54 \\
\hline 12 & -13.3934 & -18.501 & -17.8987 & -13.5632 & 0.24 & 0.26 \\
\hline 89 & -10.4223 & $\begin{array}{l}-23.128 \\
-\end{array}$ & -23.0511 & -11.7788 & 0.01 & 2.10 \\
\hline
\end{tabular}

注: $\mathrm{S}_{\mathrm{HH}} 、 \mathrm{~S}_{\mathrm{HV}} 、 \mathrm{~S}_{\mathrm{VH}} 、 \mathrm{~S}_{\mathrm{VV}}$ 表示 $\mathrm{HH} 、 \mathrm{HV} 、 \mathrm{VH} 、 \mathrm{VV}$ 极化方式的后向散射系数

\subsection{BP ANN简介}

$\mathrm{BP}$ 神经网络可以区分较为复杂系统的输入输出数据 组对间非线性的关系, 无须假定构建数学方程式 [32]。经 过优化试验, BP ANN模型为3层结构, 分别是输入层、输 出层及隐含层 $[14]$ 。综合土壤EC、地表粗䊁度、高光谱光 学特征波段、后向散射系数存在明显响应关系, 输入层定 为 11 个神经元, 分别是 $\mathrm{S}_{\mathrm{HH}} 、 \mathrm{~S}_{\mathrm{VV}} 、 \mathrm{~S}_{\mathrm{HV}} 、 \mathrm{~S}_{\mathrm{VH}} 、 \mathrm{~S}_{\mathrm{HH}} / \mathrm{S}_{\mathrm{VV}}$ 、 $\mathrm{S}_{\mathrm{HV}} / \mathrm{S}_{\mathrm{VH}}$ 、地表组合粗䊁度和 4 个光学特征波段反射率; 输 出层 1 个神经元; 隐含层 10 个神经元。用Matlab中的神 经网络工具箱来计算, 其中训练值占 $70 \%$, 验证值 $15 \%$, 模拟值 $15 \%$ 。

\section{4. 特征波段选择与模型构建}

从图 2 可以看出 $\mathrm{EC}$ 值与反射率的不同变换形式的相 关关系, 其中光谱的一、二阶导数有较好的相关性。可以 发现在一阶导数的 1403-1407nm、1806-1810nm、 $1889-1893 \mathrm{~nm} 、 2138-2142 \mathrm{~nm}$ 相关性最高, 为 $0.29 、 0.3 、 0.31$ 和 0.32 。在二阶导数的 $1584-1588 \mathrm{~nm} 、 1802-1806 \mathrm{~nm}$ 、 2201-2205nm、2344-2348nm波段相关性较高, 为 $0.27 、 0.34$ 、 $0.33 、 0.35$ 。即存在 $1802-1806 \mathrm{~nm}$ 和 $2344-2348 \mathrm{~nm}$ 。

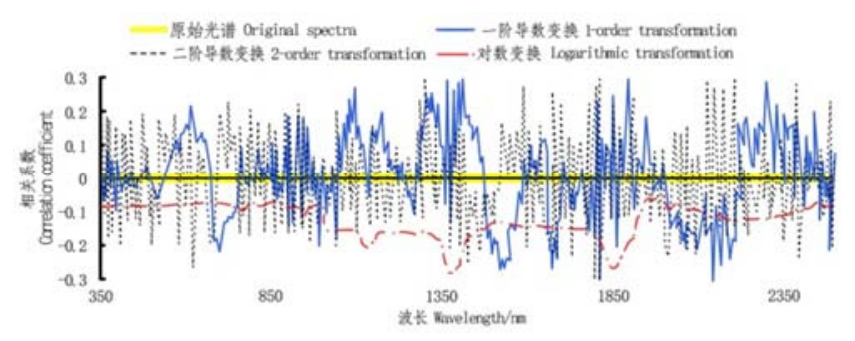

图2 土壤 $\mathrm{EC}$ 值与反射率的不同变换形式的相关性。

两个波段对土壤 $\mathrm{EC}$ 具有较好的相关性。
分别利用偏最小二乘法与相关系数法取特征波段并 拟合土壤EC值, 偏最小二乘法用波段权重来体现波段对 土壤电导率的敏感性, 见图3、4。研究发现偏最小二乘法 篎选的波段较偏后, 并且有较为敏感波段, 比如一阶导数 变换1850-1854nm波段的权重能够达到 2.5 , 二阶导数变换 中1853-1857nm与2483-2487nm权重能够达到10和3。

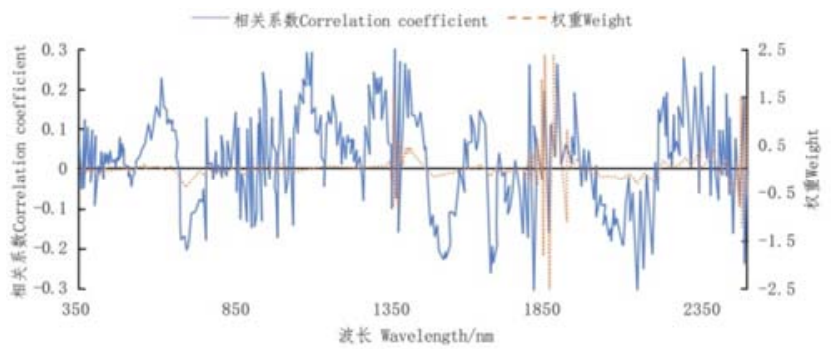

图3 土壤EC值与反射率一阶导数变换的相关性及偏最小二乘法权重分 析。

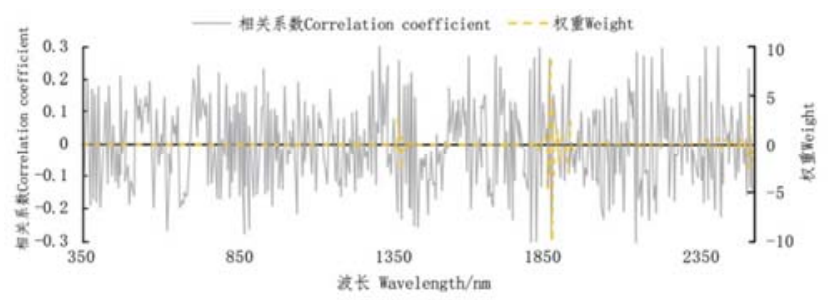

图4 土壤EC值与反射率二阶导数变换的相关性及偏最小二乘法权重分 析。

相关系数法与偏最小二乘法拟合结果见表 2 , 二阶导 数变换拟合结果优于一阶导数变换, 说明二阶导数变换更 适合于土壤 $\mathrm{EC}$ 值的拟合; 相比较使用偏最小二乘法拟合 的结果, 判定系数 $\mathrm{R}^{2}$ 和均方根误差均优。

土壤 $\mathrm{EC}$ 与光谱二阶导数回归方程: 


$$
\begin{aligned}
& Y=-33.711+9.648 * 10^{4} X_{1584}-1.22 * 10^{4} X_{1802} \\
& +4.913 * 10^{4} X_{2201}+1.054 * 10^{4} X_{2344}-0.5 S_{H H} \\
& -1.822 S_{H V}+1.826 S_{V H}+0.59 S_{V V}-4.634 S_{H H} / S_{V V} \\
& -27.719 S_{H V} / S_{V H}-12.723 Z_{S}
\end{aligned}
$$

其中, $X_{1584} 、 X_{1802} 、 X_{2201} 、 X_{2344}$ 分别为光谱二 阶导数 $1584-1589 \mathrm{~nm} 、 1802-1807 \mathrm{~nm} 、 2201-2206 \mathrm{~nm}$ 、 2344-2349nm的波段的算术平均数。

表2 相关系数法与偏最小二乘法拟合结果对比。

\begin{tabular}{llll}
\hline \multirow{2}{*}{ 方法 } & 光谱形式 & 土壤EC值 & \\
\cline { 3 - 4 } & $\mathbf{R}^{2}$ & $\mathbf{R M S E}$ \\
\hline \multirow{2}{*}{ 相关系数法 } & 一阶导数 & 0.067 & 11.348 \\
\multirow{2}{*}{ 偏最小二乘法 } & 二阶导数 & 0.170 & 11.314 \\
& 一阶导数 & 0.158 & 2.382 \\
& 二阶导数 & 0.227 & 2.302 \\
\hline
\end{tabular}

神经网络模型建立使用Matlab工具箱（nprtool），训 练值占 $70 \%$, 验证值 $15 \%$, 模拟值 $15 \%$, 隐藏层设置为 10 层。神经网络模型 $\mathrm{R}^{2}$ 为 0.8666 , 优于经验模型, 见图5。

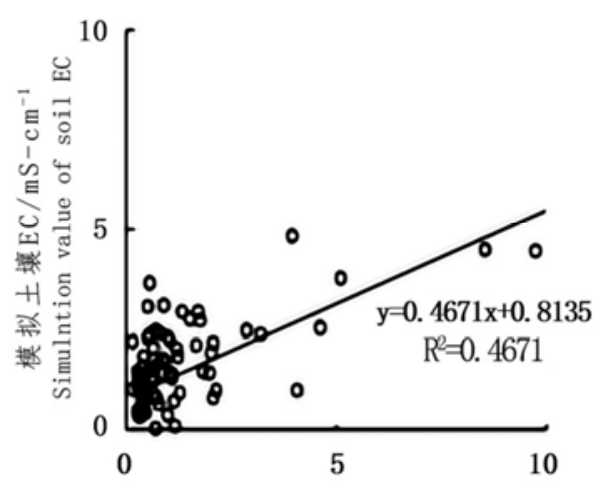

实测土壤 $\mathrm{EC} / \mathrm{mS}^{-} \mathrm{cm}^{-1}$

Measured value of soil EC

(a) 土壤EC实测与经验模型模拟值

(a) Measured and empinical model simulation value of soil EC

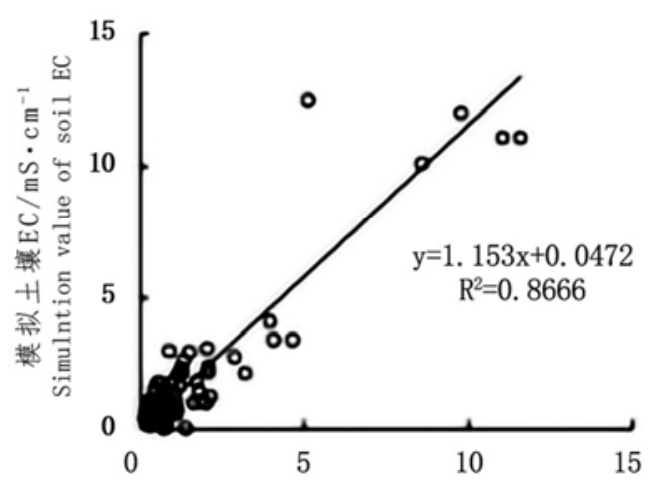

实测土壤 $\mathrm{EC} / \mathrm{mS} \cdot \mathrm{cm}^{-1}$

Measured value of soil EC

(b) 土壤EC实测与神经网络模拟值

(b) Mensured and neural net simulation value of soil EC

图5 土壤 $\mathrm{EC}$ 实测与模拟值。
按照表 3 , 将区域划分为 5 类研究类型, 分别是 I - 非 盐渍土、II -轻度盐渍土、III-中度盐渍土、IV-重度盐渍土 及 $V$-盐碱土[33]。雷达参数与MSR选择的二阶导数三个特 征波段建立的回归方程模型模拟的EC预测结果见图6, 在 ENVI运算模拟结果[21], 见表4, 结果显示盐碱地面积占

\begin{tabular}{|c|c|c|c|c|c|}
\hline 级别 & I & II & III & IV & $\bar{V}$ \\
\hline 土壤EC & $<0.34$ & $0.34-0.38$ & $0.38-0.48$ & $0.48-0.73$ & $>0.73$ \\
\hline \multicolumn{6}{|c|}{$\begin{array}{l}\text { 注: } I \sim V \text { 级分别代表非盐渍土、弱盐渍土、中盐渍土、重盐渍土和盐 } \\
\text { 土 }\end{array}$} \\
\hline \multicolumn{6}{|c|}{ 表4 土壤EC预测图各等级占比。 } \\
\hline 级别 & $\mathrm{I}$ & II & III & IV & $\overline{\mathrm{V}}$ \\
\hline $\begin{array}{l}\text { 各等级 } \\
\text { 占比 } / \%\end{array}$ & 3.02 & 20.54 & 64.42 & 11.44 & 0.58 \\
\hline
\end{tabular}
比 $96.98 \%$, 值得重视的是中度盐渍化面积占比近 $65 \%$, 而 重度盐碱土和盐碱土占比 $12.02 \%$ 。

表3 土壤EC盐渍化分类表。

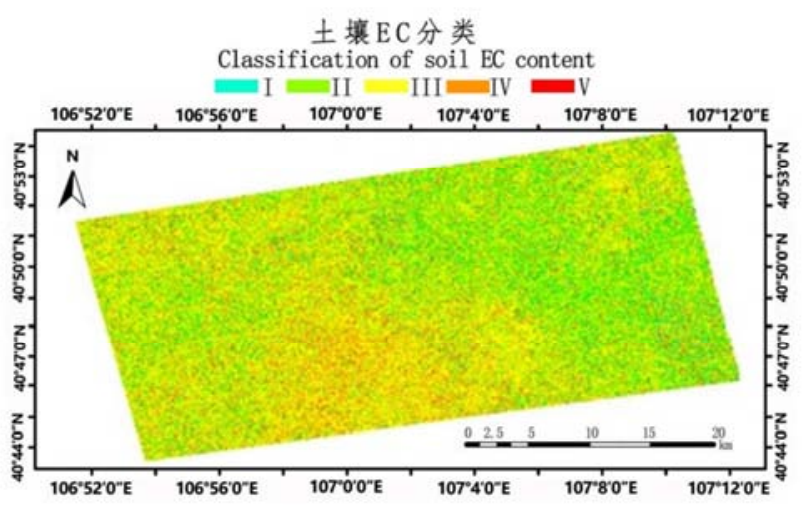

图6 研究区土壤EC预测图。

\section{5. 结论}

1) 对光谱进行不同形式的变换处理能够提升光谱反 射率与土壤EC的关系。文章经过PLSR及MSR选择特征波 段, 光谱一、二阶导数相关性较好, 特别是二阶导数的四 个波段相关性比较强, 分别是1584-1588nm、1802-1806nm、 2201-2205nm、2344-2348nm波段。

2) 通过协同光谱特征波段反射率二阶倒数、地表粗 糙度及雷达后向散射系数等因子, 对比土壤电导率的 PLSR 与MSR模型, 发现BP神经网络模型为最佳预测模 型, 其模型预测 $R^{2}$ 为 0.8666 , 模型稳定性和预测精度均优 良。多源遥感数据源神经网络模型在综合高光谱特征波 段、SAR后向散射系数和地表粗糙度参数后具备较大优 势。

本文拟合的经验模型依赖于地表实验且有一定的地 域局限性, 今后的研究需要扩大土壤电导率反演模型的普 适性。下一步盐渍地盐分遥感预测模型须加强与中高分辨 率卫星光学影像数据的结合 [34], 针对植被覆盖条件下的 灌区土壤条件, 试验多尺度、多时相的多源遥感大数据动 态监测, 实现区域盐碱地盐分精确反演, 丰富灌区盐渍化 
防治的技术手段。同时建立土壤光谱数据库, 实现河套灌 区土壤光谱数据共享, 为研究提供数据支持。

\section{致谢}

国家自然科学基金项目（52069020）；内蒙古农业大 学 “双一流”学科创新团队建设人才培育项目 (NDSC2018-10)。

\section{参考文献}

[1] 李相君.河套灌区土壤盐分多源遥感数据协同反演 $[D]$. 内蒙 古农业大学,2017.

[2] 王学.盐渍化灌区土壤介电特性与多源遥感水分反演研究 [D].内蒙古农业大学, 2017 .

[3] 张飞.干旱区绿洲盐渍化地光谱、空间特征与成分研究[D]. 新疆大学,2007.

[4] J FARIFTEH, A FARSHAD, R J GEORGER.Assessing salt-affected soils using remote sensing,solute modelling, and geophysics[J].Geoderma., 2006, 130: 191-206.

[5] J FARIFTEH, F VANDER MEER, C ATZBERGER,et al. Quantitative analysis of salt-affected soil reflectance spectra:A comparison of two adaptive methods (PLSR and ANN)[J].Remote Sensing of Environment, 2007, 110: 5978.

[6] JIMENEZ L O, MEDINA J L R, DIAZ E R,et al.Integration of spatial and spectral information by means of non-supervised Extraction and classification for homogeneous objects applied to multispectral and hyperspectral Data[J]. IEEE Transactions on Geoscience and Remote Sensing, 2005,43(4): 844-851.

[7] BRUNNER P, LI H T, KINZELBACH W, et al.Generating soil electrical conductivity maps at regional level by integrating measurements on the ground and remote sensing data[J].International Journal of Remote Sensing, 2007, 28(15):3341-3361.

[8] 王静,刘湘南,黄方,等.基于ANN技术和高光谱遥感的盐渍 土盐分预测[J].农业工程学报,2009,25(12):161-166.

[9] VALERIANO M M, EPIPHANIO J C N, FORMAGGIO A R, et al. Bi-directional reflectance factor of 14 soil classes from Brazil[J]. International Journal of Remote Sensing, 1895,16(1): $113-128$.

[10] SCHAAP M G, LEIJ F J.Using neural networks to predict soil water retention and soil hydraulic conductivity[J]. Soil \&Tillage Research, 1898, 47(1/2): 37-42.

[11] WALTHALL C, DULANVEY W, ANDERSON M, et al.A comparison of empirical and neural network approaches for estimating cornand soybean leaf area index from Landsat ETM+ imagery[J].Remote Sensing of Environment, 2004, 92(4): $465-474$.
[12] TADJUDIN S, LANDGREBE D A.Covariance estimation with limited training samples[J]. IEEE Transactions on Geoscience and Remote Sensing, 1899, 37 (4): 2113-2118.

[13] BEHRENS T, FORSTTER H, SCHOLTEN T, et al.Digital soil mapping using artificial neural networks[J]. Journal of Plant Nutrition and Soil Science, 2005, 168(1): 55-62.

[14] 刘全明, 成秋明, 王学, 等.河套灌区土壤盐渍化微波雷达 反演[J]. 农业工程学报，2016，32(16)：109-114.

[15] 孙艺珊. 吉林省西部盐渍土电导率的遥感反演及三十年时 序变化研究[D].中国科学院大学(中国科学院东北地理与农 业生态研究所),2020.

[16] 尼格拉. 塔什甫拉提.渭干河一库车河三角绿洲土壤盐渍化 遥感与近感协同监测方法研究[D].新疆大学,2014.

[17] 牛涛.基于地表定量参数的土壤电导率反演模型研究[D].新 疆大学,2013.

[18] 郭姝姝.基于遥感及CLUE-S模型的内蒙古河套灌区土壤盐 渍化时空演变与调控研究 [D]. 中国水利水电科学研究 院,2018.

[19] 彭杰,王家强,向红英,等.土壤含盐量与电导率的高光谱反演 精度对比研究 [J]. 光谱学与光谱分析,2014,34(02):510-514.

[20] 刘广明, 吴亚坤, 杨劲松, 等.基于电磁感应技术的区域三 维土壤盐分空间变异研究 [J/OL]. 农业机械学报, 2013,44(7): 78-82.

[21] 冯雪力,刘全明.基于多源遥感协同反演的区域性土壤盐渍 化监测[J].农业机械学报，2018,49（07）:127-133.

[22] 李彪,王耀强. 寒旱灌区含盐土壤水分雷达反演技术研究 [J]. 江苏农业科学,2015,43(02):347-350.

[23] 黎明扬,刘廷尔,罗艳云, 等.半干旱草原型流域表层土壤饱和 导水率传递函数及遥感反演研究 [J]. 土壤学 报,2019,56(01):90-100.

[24] 王学,刘全明,马腾.西北寒旱灌区裸露地表粗䊁度SAR反演 建模方法研究[J].灌溉排水学报,2017,36(06):74-80.

[25] 贾永倩,王振锡,㫿余红,等.基于全极化Radarsat-2数据的苹 果园平均树高估算模型[J].森林工程,2017,33(02):45-49+55.

[26] 黎明扬. 半干旱草原型流域土壤入渗参数模拟及遥感反演 研究[D].内蒙古农业大学,2019.

[27] 王釒梅,牟洪香,杨可伟,等.不同氮素水平下 107 杨光谱及光 合响应特征研究 [J]. 南京林业大学学报 (自然科学 版),2016,40(03):70-74.

[28] 李炎,王让会,管延龙,等.基于高光谱反射特性的土壤全氮含 量预测分析 [J].遥感技术与应用,2017,32(01):173-179.

[29] 熊逸邀. 城镇化发展与利率调整对房地产需求的影响研究 [D].湘潭大学, 2018 .

[30] 王迪.辽宁中部城市建成区空间形态对生活性碳排放影响 研究[D]. 沈阳建筑大学, 2018 . 
[31] 彭清维,刘芸,于建成, 等.基于可见/近红外光谱技术的湄潭 翠芽等级判别[J]. 茶叶科学,2017,37(05):458-464.

[32] 刘全明,陈亚新,王耀强,等.基于 $\mathrm{BP}$ 神经网络技术的土壤水 (盐) 环境监测 $[\mathrm{J}]$. 内蒙古农业大学学报 (自然科学 版),2006, \{4\}(04):105-109.
[33] 梁东.博斯腾湖湖滨绿洲土壤盐渍化预警研究[D].新疆师范 大学, 2015 .

[34] 李荣荣,熊黑钢,段鹏程,等.干旱区平原水库下游盐渍化土壤 光谱时空分布特征分析 [J].土壤通报,2016,47(03):532-536. 